\title{
Mosaic Somatic Gene Recombination as a Potentially Unifying Hypothesis for Alzheimer's Disease
}

\author{
Gwendolyn E. Kaeser and Jerold Chun* \\ Sanford Burnham Prebys Medical Discovery Institute, La Jolla, CA, United States
}

The recent identification of somatic gene recombination (SGR) in human neurons affecting the well-known Alzheimer's disease (AD) pathogenic gene, amyloid precursor protein (APP), has implications for the normal and the diseased human brain. The amyloid hypothesis has been the prevailing theory for sporadic $A D(S A D)$ pathogenesis since the discovery of APP gene involvement in familial $A D$ and Down syndrome.

OPEN ACCESS

Edited by:

Svetlana G. Vorsanova Veltischev Research and Clinical Institute for Pediatrics of the Pirogov Russian National Research Medical University, Russia

Reviewed by:

Thomas Liehr

Friedrich Schiller University Jena,

Germany

Fabio Coppedè,

University of Pisa, Italy

Antoneta Granic,

Newcastle University, United Kingdom

${ }^{*}$ Correspondence: Jerold Chun jchun@sbpdiscovery.org

Specialty section: This article was submitted to Human Genomics,

a section of the journal

Frontiers in Genetics

Received: 12 December 2019

Accepted: 27 March 2020

Published: 07 May 2020

Citation:

Kaeser GE and Chun J (2020) Mosaic Somatic Gene Recombination as a Potentially Unifying Hypothesis

for Alzheimer's Disease.

Front. Genet. 11:390.

doi: 10.3389/fgene.2020.00390
Yet, despite enormous scientific and clinical effort, no disease-modifying therapy has emerged. SGR offers a novel mechanism to explain $A D$ pathogenesis and the failures of amyloid-related clinical trials, while maintaining consistency with most aspects of the amyloid hypothesis and additionally supporting possible roles for tau, oxidative stress, inflammation, infection, and prions. SGR retro-inserts novel "genomic complementary DNAs" (gencDNAs) into neuronal genomes and becomes dysregulated in SAD, producing numerous mosaic APP variants, including DNA mutations observed in familial AD. Notably, SGR requires gene transcription, DNA strand-breaks, and reverse transcriptase (RT) activity, all of which may be promoted by well-known AD risk factors and provide a framework for the pursuit of new SGR-based therapeutics. In this perspective, we review evidence for APP SGR in AD pathogenesis and discuss its possible relevance to other AD-related dementias. Further, SGR's requirement for RT activity and the relative absence of AD in aged HIV -infected patients exposed to RT inhibitors suggest that these Food and Drug Administration (FDA)-approved drugs may represent a near-term disease-modifying therapy for AD.

Keywords: Alzheimer's disease, mosaicism, somatic gene recombination, amyloid cascade hypothesis, gencDNA, amyloid precursor protein, APP

\section{GENOMIC MOSAICISM AT THE APP LOCUS}

We first speculated that SGR might exist in the brain based upon the expression of immunological recombination genes, as described over a quarter century ago for recombination activating gene-1 (Chun et al., 1991) and later, non-homologous end-joining genes (Gao et al., 1998). Subsequent studies to identify somatically generated genomic mosaicism in the human brain identified chromosomal aneuploidies that represent large CNVs

Abbreviations: $\mathrm{AD}$, Alzheimer's disease; APP, amyloid precursor protein; $\mathrm{CNV}$, copy number variation; DISH, DNA in situ hybridization; gencDNA, genomic complementary DNA; PNA-FISH, peptide nucleic acid fluorescent in situ hybridization; RT, reverse transcriptase; $\mathrm{SAD}$, sporadic $\mathrm{AD}$; SGR, somatic gene recombination. 
(Rehen et al., 2001). The application of newer technologies including fluorescence-activated nuclear sorting (Rehen et al., 2005; Westra et al., 2010) and single-cell sequencing expanded the discovery of somatically arising genomic mosaicism forms, revealing an immense diversity of DNA sequence differences present among single cells (reviewed in Rohrback et al., 2018). This includes Jackson Pollock-like displays reflective of enormous single-cell transcriptome diversity in the brain (Lake et al., 2016, 2018) that is consistent with genomic mosaicism. Neuronal genomic mosaicism takes many forms including aneuploidies, CNVs, single nucleotide variations (SNVs), and long interspersed nuclear element 1 (LINE1). Some of these have been associated with neurodegenerative (including $\mathrm{AD}$ ) and neuropsychiatric disorders, which have been reviewed extensively and will not be the subject of this perspective (Arendt et al., 2009; Leija-Salazar et al., 2018; Rohrback et al., 2018; Shepherd et al., 2018; Iourov et al., 2019; Potter et al., 2019).

Although the existence of genomic mosaicism is now established, its functions are less clear. Roles in transcriptomic regulation (Kaushal et al., 2003), cell survival (Peterson et al., 2012), and neural circuits (Kingsbury et al., 2005) have been reported, and others have speculated on the importance of genomic mosaicism in the creation of neuronal diversity (Rehen et al., 2001, 2005; Muotri and Gage, 2006; Gericke, 2008), yet these general phenomena did not reveal effects on specific genes or DNA alterations that might be analogous to $\mathrm{V}(\mathrm{D}) \mathrm{J}$ recombination in the immune system (Papavasiliou and Schatz, 2002). However, a candidate gene emerged when we observed increases in a major sub-type of mosaicism called "DNA content variation" (Westra et al., 2010) in SAD neurons of the prefrontal cerebral cortex, where SAD neurons contained $\sim 500$ megabase pairs more DNA than the non-diseased controls (Bushman et al., 2015). We reasoned that the increase could affect APP, a key gene in $\mathrm{AD}$ pathogenesis that is causal in familial $\mathrm{AD}$ and Down syndrome through mutations and, in particular, CNVs: mosaically increased APP CNVs in SAD brains may drive pathology. This possibility was confirmed using multiple approaches including PNA-FISH, small-population qPCR, and single-neuron qPCR, which demonstrated that somatic and mosaic changes to the APP locus were enriched in SAD neurons over non-diseased controls and were not associated with trisomy of chromosome 21 (Bushman et al., 2015). Interestingly, PNAFISH targeting individual APP exons and exon-exon copy number discordance by single-cell qPCR suggested that the physical arrangement of APP CNVs could be non-uniform (Bushman et al., 2015).

Additional studies confirmed this possibility and revealed SGR at the $A P P$ locus (Figure 1A), occurring as variant $A P P$ coding sequences that lacked introns and were akin to complementary DNA (cDNA) sequences except that they were present in genomic DNA and were therefore termed "gencDNAs" (Figure 1B) (Lee et al., 2018). These novel gencDNAs were further characterized by intra-exonic junctions with shared microhomology regions between the two joined exonic regions. Identical forms were also documented in mRNAs. The formation of $A P P$ gencDNAs in vitro required $A P P$ transcription, DNA strand breakage, and RT activity. Neuronal SGR represents a novel mechanism to produce genomic mosaicism that has functional implications, particularly for $\mathrm{AD}$ pathogenesis and therapeutics, while suggesting a more general paradigm underlying sporadic brain diseases through dysregulated SGR of both known and unknown pathogenic genes.

\section{SGR AFFECTING APP IS DYSREGULATED IN SAD BRAINS}

At least 12 distinct approaches, including non-targeted and unbiased methods, were used to identify and validate somatic mosaic events at the APP locus (Bushman et al., 2015; Lee et al., 2018; Lee et al., 2019). SGR was identified in both normal and diseased brains but appears to be dysregulated with disease, resulting in dramatic increases to both the number and the form of APP gencDNAs in SAD neurons. Novel approaches were utilized, including DISH and high-fidelity, long-read sequencing to establish disease alterations.

DISH was developed by modifying BaseScope (Advanced Cell Diagnostics, Fremont, CA, United States) technology that can detect SNVs (Baker et al., 2017) and exon:exon junctions in RNA but was adapted for use on genomic DNA. Probes were designed to target multiple gencDNA sequences, including the exon 16:exon 17 junction and the intra-exonic junction formed by the microhomology fusion of exon 3 to exon 16 (Figure 1B). Several parallel approaches were employed, including sense and antisense probes that demonstrated DNA specificity ( $v s$. RNA that is not recognized by sense-strand probes), targeted restriction enzyme digestion that effectively destroyed the DNA target locus and dependent signal, DISH double-labeling that indicated that gencDNA loci are distinct from the endogenous alleles, and the use of synthetic targets in cell culture that confirmed probe specificity (Lee et al., 2018). SAD brains exhibited an average of 1.2-1.8 gencDNAs per nucleus, with 60$70 \%$ of prefrontal SAD cortical neuronal nuclei having at least one signal. In contrast, the control brains averaged 0.4 gencDNAs per nucleus, and only $25 \%$ of nuclei had at least one signal. The three- to fourfold increase in SAD gencDNA number was consistent throughout all biological and technical replicates (six SAD and six non-diseased brains; three experiments per brain). Notably, detection by this technique is limited to the targeted exon:exon sequence or intra-exonic junction and, therefore, does not capture the full diversity of possible gencDNAs, including full-length or more complex structural variants.

The second novel approach to assess gencDNAs and identify disease-related differences was high-fidelity, longread sequencing with Pacific Biosciences' single-molecule realtime circular consensus sequencing (SMRT CCS or "PacBio sequencing") (Eid et al., 2009; Hebert et al., 2018), which is capable of identifying SNVs with $99.999999 \%$ confidence. APPtargeted PCR products were amplified from neurons (five SAD and five non-diseased brains) and sequenced. These experiments revealed enormous gencDNA diversity involving thousands of unique species. Importantly, gencDNA sequences changed significantly with disease, despite identical PCR targeting that involved amplification with exon 1 and 18 primers (myriad other 
A APP genomic locus and full-length cDNA (APP-770)

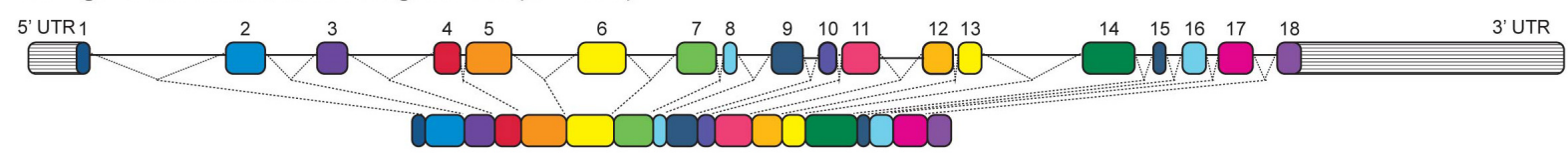

B Types of gencDNAs identified

Full-length brain-specific isoforms

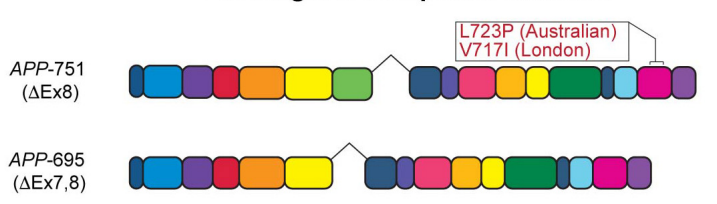

Intra-exonic junctions with microhomology and SNVs

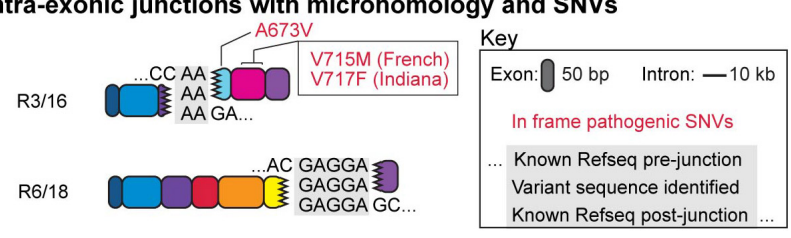

FIGURE 1 | Structure of a gencDNA. (A) The APP genomic locus and the exons within a full-length cDNA. (B) Two types of gencDNAs were identified in both RNA and DNA: full-length brain-specific isoforms (APP-751 and APP-695) and truncated sequences with intra-exonic junctions and microhomology domains (R3/16 and R6/18). Known pathogenic SNVs were also identified in some variants (in-frame examples include Australian, London, French, Indiana, and A673V; shown in red). Figure modified from Lee et al. (2018).

species may exist). The SAD brains had 10 times more unique reads per neuronal nucleus, and we identified 45 unique intraexonic junctions in SAD brains, contrasting with just 20 unique intra-exonic junctions found in non-diseased brains despite using $\sim 70 \%$ more neuronal nuclei. Most remarkably, PacBio sequencing identified 11 mosaic SNVs in or around the $A \beta$ encoding region that are considered to be disease-causing in familial $\mathrm{AD}$, present only in SAD neurons. The results from DISH and PacBio sequencing together confirm that normal human neurons display a baseline level of APP gencDNAs that is increased and fundamentally altered in number and form with $\mathrm{AD}$, including the formation of pathogenic SNVs. Independent support for gencDNAs was recently published by an unrelated laboratory (Lee et al., 2019; Park et al., 2019). Preliminary analyses of these data identified diverse integration sites for gencDNAs on multiple chromosomes (Lee et al., 2019) and are consistent with DISH signals that were distinct from wild-type (chromosome 21) alleles (Lee et al., 2018).

\section{MOLECULAR DIVERSITY PRODUCED BY SGR MAY LINK MULTIPLE AD HYPOTHESES}

Somatic gene recombination likely has normal functions; however, it appears to be dysregulated in $\mathrm{AD}$, most likely during the proposed cellular phase of $\mathrm{AD}$ (critically reviewed in De Strooper and Karran, 2016). SGR could create variant $A P P$ sequences that become translated into heterogeneous populations of APP variant and A $\beta$-like proteins-in addition to serving as more classical secretase substrates to generate $A \beta-$ that could result in myriad downstream biochemical processes, as was reported for AD. SGR of APP could have effects on primary, secondary, tertiary, or quaternary protein structure and therefore could have a vast array of functional effects, including those related to prions. The heterogeneity of APP forms produced by SGR invokes modification of the amyloid hypothesis to integrate this new feature while still maintaining decades of supportive observations. SGR also accounts for experimental discrepancies and clinical trial failures. In doing so, it may unify other hypotheses of SAD etiology and pathogenesis via a modified amyloid hypothesis (Figure 2). Other pathogenic actions of SGR, such as those produced by the integration of mobile elements, may also be relevant. The initial views on the implications of SGR in AD (Castro et al., 2019; Lee and Chun, 2019) are expanded upon next.

\section{Amyloid Cascade Hypothesis Modified by Somatic Gene Recombination}

The amyloid cascade hypothesis (or the amyloid hypothesis) has been the predominant AD theory for decades (Hardy and Higgins, 1992; Hardy and Selkoe, 2002; Selkoe and Hardy, 2016), having emerged through the identification of amyloid- $\beta(A \beta)$ as the plaque-forming peptide from $\mathrm{AD}$ and Down syndrome brains 35 years ago (Glenner and Wong, 1984a,b), which allowed the subsequent identification of $A P P$ as the gene locus responsible for A $\beta$ (Goldgaber et al., 1987; Tanzi et al., 1987b). The strongest evidence for the involvement of $A P P$ and its cleavage product $\mathrm{A} \beta$ in $\mathrm{AD}$ comes from familial $\mathrm{AD}$ and Down syndrome studies. Familial AD exhibits typical Mendelian inheritance of mutations or CNVs in APP or mutations in the secretase genes, PSEN1 (Sherrington et al., 1995) and PSEN2 (Levy-Lahad et al., 1995; Rogaev et al., 1995) that alter A $\beta$ processing and lead to early-onset AD. APP shows a clear gene dosage effect, where three copies of $A P P$ in Down syndrome (Wiseman et al., 2015) or rare familial AD cases (Rovelet-Lecrux et al., 2006; Sleegers et al., 2006; Hooli et al., 2012) are sufficient to produce $\mathrm{AD}$ neuropathology and/or symptomology. In the amyloid hypothesis, the accumulation of $\mathrm{A} \beta$ in the brain and its aggregation into plaques result in downstream processes that lead to hyperphosphorylation of tau, resultant neurofibrillary tangles (NFTs), synaptic dysfunction, cell death, and ultimately AD.

One major criticism of the amyloid hypothesis is the timing of plaque deposition. A $\beta$ plaques do not necessarily correlate well with cognitive impairment, and many individuals have 


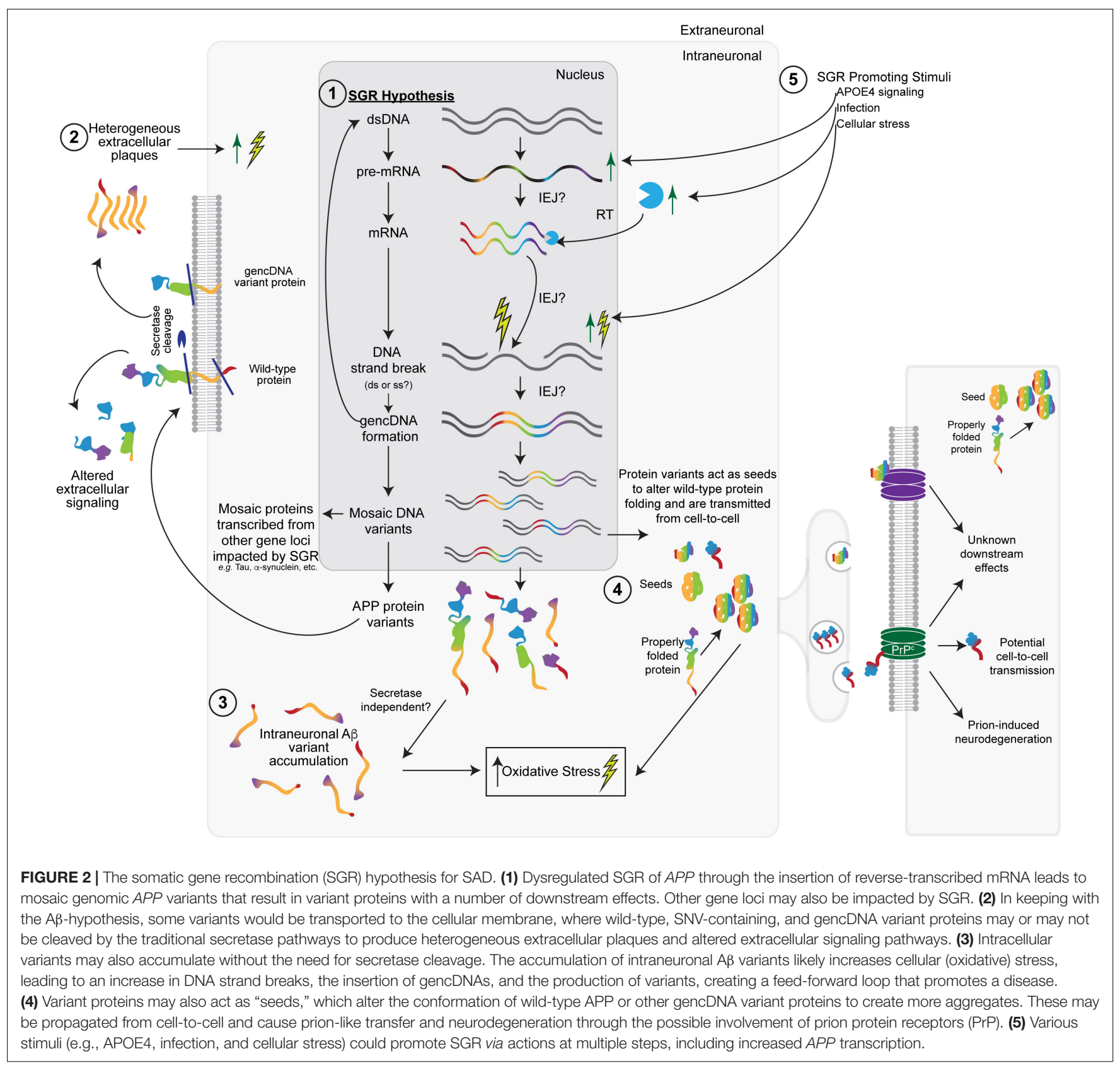

abundant $\mathrm{A} \beta$ deposits at death and yet were cognitively normal antemortem (Crystal et al., 1988; Katzman et al., 1988; Troncoso et al., 1996). These plaques tend to be more diffuse with lower levels of $A \beta$ oligomers (Esparza et al., 2013), which suggests that pathogenic plaques sequester toxic oligomers (Selkoe and Hardy, 2016). Additionally, there is evidence that the duration of plaque deposition is more predictive of SAD (Insel et al., 2017) rather than the presence of plaques per se. Another major criticism of the amyloid hypothesis has been its failure to yield any diseasemodifying therapies despite the many clinical trials targeting $A \beta$ components (Carlsson, 2008; Cummings et al., 2014; Anderson et al., 2017; Mehta et al., 2017; Burki, 2018; Egan et al., 2018). These discrepancies and others have led to calls to abandon or fundamentally rethink the amyloid hypothesis (Herrup, 2015; Morris et al., 2018).

However, these major discrepancies may be explained by SGR. SGR may generate diverse APP protein products, including A $\beta$ and $A \beta$-like molecules, on a continuum of toxicity within plaques and as soluble proteins. Therefore, SGR of APP incorporates supportive data for the amyloid hypothesis in SAD by vastly expanding the gene forms, including those containing pathogenic SNVs, and resulting protein products associated with amyloid (Figure 2). These products would access downstream pathogenic cellular mechanisms observed in familial AD but doing so mosaically and somatically in SAD. SGR affecting APP also provides an opportunity to reconsider clinical trial failures. All 
therapeutic antibodies against $A \beta$ are monoclonal, which target distinct epitopes of a conserved amino acid sequence of $A \beta$ (Arndt et al., 2018), and many antibodies are effective at clearing the plaques formed by this amino acid sequence. However, SGR creates myriad different $A P P$ variant genes, transcripts, and predicted amyloid proteins that may not be recognized by mono-specific $A \beta$-antibodies. These variant species would therefore remain in the brain in various potential forms (e.g., other plaques, fibrils, prions, and soluble products). Notably, some forms arising from gencDNAs will share conserved epitopes that may be accessed by mono-molecular agents to affect a subset of gencDNAs providing partial efficacy. Similarly, SGR may create products that do not require secretase cleavage, a view supported by the small size of some variant genes and RNA transcripts (Figure 2). Taken together, SGR maintains the central genetic importance of $A P P$ in familial forms of $\mathrm{AD}$ and Down syndrome but significantly extends it to account for SAD without requiring germline changes in $A P P$.

Any AD hypothesis must account for statistical relationships to $\mathrm{AD}$ risk genes (Kunkle et al., 2019). In this regard, SGR could be augmented by risk genes like APOE4, the major risk allele for AD (Saunders et al., 1993; Strittmatter et al., 1993) that has been shown to increase $A P P$ transcription and $A \beta$ deposition (Huang et al., 2017; Liu et al., 2017). This function of APOE4 is highly consistent with the SGR hypothesis, where $A P P$ transcription was shown to be required for gencDNA formation in culture and in J20 mouse neurons. Increases in $A P P$ transcription could therefore increase the probability of $A P P$ SGR occurring, and gencDNA production could lead to SGR-dependent "seeds" that promote toxic plaque deposition. Other risk genes could similarly interface with SGR to produce somatic, disease-promoting genomic changes. Notably, PSEN1 variants were not identified using the same detection pipeline that identified APP gencDNAs. One possibility is that the gain-offunction end-points that appear to occur for APP are not relevant to the promotion of AD by PSEN1 mutations, a view consistent with the scientific literature that identifies loss-of-function rather than gain-of-function mechanisms (Kelleher and Shen, 2017; Sun et al., 2017).

\section{Tau Hypothesis Compatibility With SGR}

Tau is a microtubule-associated protein that becomes hyperphosphorylated in disease and can aggregate to form NFTs, the second major pathological hallmark of AD (Braak and Braak, 1991; Braak et al., 2006). Tau pathology is closely correlated with neurodegeneration and clinical symptoms (Ossenkoppele et al., 2016; Scholl et al., 2016; Okamura and Yanai, 2017) and may be a key initiator of stressors leading ultimately to cell death in both the A $\beta$ and tau hypotheses (Selkoe and Hardy, 2016; Kametani and Hasegawa, 2018).

Somatic gene recombination is consistent with the tau hypothesis in two distinct and non-mutually exclusive ways. First, SGR generates APP protein variants that could alter tau phosphorylation and processing: a function proposed for $A \beta$ (Rapoport et al., 2002; Dolan and Johnson, 2010; Jin et al., 2011;
Moore et al., 2015). Second, SGR might act on the gene for tau$M A P T$-in the same manner as $A P P$, thereby creating myriad and mosaic $M A P T$ variants (Figure 2). MAPT mutations are known to cause autosomal dominant forms of frontotemporal lobar degeneration (FTLD) and Parkinson's disease (PD), with over 40 pathogenic mutations identified to date (Rademakers et al., 2004; Ghetti et al., 2015), and SGR could generate related SNVs. There is some debate on whether germline MAPT mutations also represent an increased risk for developing $\mathrm{AD}$; however, a recent meta-analysis of a subset of SNVs reported a significantly increased risk for $\mathrm{AD}$ that was furthered by APOE4 carrier status (Zhou and Wang, 2017). If MAPT were mosaically altered in SAD brains, but perhaps in different cells or brain regions, it might contribute to $\mathrm{AD}$ progression, and importantly, explain the high co-morbidity between $\mathrm{AD}$ and PD/other proteinopathies (Kovacs et al., 2013; Brenowitz et al., 2017; Kapasi et al., 2017); further study is warranted.

\section{Prion Hypothesis Relevance to SGR}

Prions are misfolded proteins that are able to transmit disease in a fashion similar to an infection, via transfer of proteins from cell to cell (Watts and Prusiner, 2018). Evidence has been steadily mounting for the involvement of prions in SAD and other neurodegenerative diseases (e.g., PD and FTLD) in which misfolded proteins are prone to accumulation. Both A $\beta$ (Jaunmuktane et al., 2015; Olsson et al., 2018) and tau (Holmes and Diamond, 2014; Alonso et al., 2016; Kaufman et al., 2016) have been implicated as prion proteins in AD. The enormous potential protein heterogeneity encoded by SGR gene variants is well suited to create DNA sequences encoding mutant prion-like proteins (Figure 2). Such proteins may have seeding effects, leading to the misfolding of normal APP and $A \beta$-or other SGR-derived proteins-which could then act as prionlike transmissible agents. Were this to occur, SGR variants may impact neighboring cells, perhaps via the prion protein receptor itself (Lauren et al., 2009; Gimbel et al., 2010), thereby amplifying the spread of pathogenic SGR products. This mechanism might enable propagation throughout the $\mathrm{AD}$ brain to promote the documented neuroanatomical progression of plaques and tangles (Arnold et al., 2013). SGR might also enable the identification of key pathological amino acid sequences in prion-like proteins.

\section{Inflammation and Cellular Stress Hypotheses and SGR}

There are multiple hypotheses for SAD that incorporate some component of the inflammation pathway, oxidative stress, biometal accumulation, and/or mitochondrial dysfunction. These mechanisms likely combine to accelerate neurodegeneration. However, there is debate about whether these processes cause neurodegeneration or are the result of it (Andersen, 2004). Indeed during an inflammatory response, glia produce high levels of free radicals that promote cellular damage and augment neuroinflammation (Solleiro-Villavicencio and Rivas-Arancibia, 2018); thus, the mechanisms underlying such hypotheses are likely to involve a multifaceted, cyclical mechanism of neurodegeneration. 
As a class, transposable elements have complex roles in cellular stress (Horvath et al., 2017) that may be emulated or impacted by gencDNAs. Cellular stress causes nucleic acid oxidation which often results in strand breaks. DNA strand breaks were shown to be required for SGR retro-insertion and gencDNA formation in cell culture (Lee et al., 2018). It is therefore possible that a feed-forward mechanism exists where cellular stress causes the strand breaks that enable SGR of APP gencDNAs, whose products would, in turn, increase oxidative stress (Figure 2). Additionally, both DNA and RNA oxidation occur in AD brains (Nunomura et al., 1999, 2012); the resultant DNA strand breaks may promote dysregulated gencDNA retro-insertion and could contribute to the formation of intra-exonic junctions.

\section{Trisomy 21 Hypothesis and SGR}

Trisomy of chromosome 21 has long been associated with AD through Down syndrome and the first identification of APP, leading to early hypotheses that SAD might be caused by trisomy 21 . This hypothesis was rigorously tested in 1987 and no duplication of chromosome 21 (St George-Hyslop et al., 1987) or the APP gene (Tanzi et al., 1987a) was found in bulk samples of SAD brains. Reports on linkage between global mosaic trisomy 21 and SAD have been reviewed elsewhere (Potter, 1991; Potter et al., 2016, 2019). It is notable that mosaic aneuploidies involving all chromosomes are found throughout the normal vertebrate brain, including humans, independent of $\mathrm{AD}$ (reviewed in Arendt et al., 2009; Leija-Salazar et al., 2018; Rohrback et al., 2018; Shepherd et al., 2018; Iourov et al., 2019; Potter et al., 2019). While some studies have reported an increase in brain aneuploidies associated with AD (Iourov et al., 2009; Arendt et al., 2010; Yurov et al., 2014), others have not identified disease associations (Thomas and Fenech, 2008; Westra et al., 2009; Bushman et al., 2015). Critically, sampling issues affect all studies of aneuploidy because of the minute fraction of interrogated cells utilized compared to the total number of cells within the brain. Interestingly, increased gene transcription could theoretically increase the probability of SGR for a given gene, in support of a link between chromosomal gains that promote transcription and SGR.

\section{Infection Hypothesis and SGR}

The infection or pathogen hypothesis proposes that viral, fungal, and/or bacterial infections may trigger $\mathrm{AD}$. These hypotheses are based on reports of the presence of viruses, fungi, or bacteria (or their remnant signatures) within the SAD brain (Hill et al., 2014; Itzhaki et al., 2016; Harding et al., 2017). Some viruses, including human immunodeficiency virus (HIV) and hepatitis B virus (HBV) (Mastroeni et al., 2018), as well as certain bacteria (Lampson et al., 2005), possess demonstrated RT activity-a requirement for SGR. In addition, the vast diversity of APP gencDNAs could conceivably produce proteins that could bind to and possibly neutralize infectious agents by analogy to immunoglobulins in the immune system (Eimer et al., 2018). However, the causality, specificity, and presence of these infectious agents require further study, as underscored by reports of bacterial contamination as artifacts in human microbiome studies (reviewed in Eisenhofer et al., 2019).

\section{The SGR Hypothesis in AD}

The preceding discussion outlines concepts and hypotheses that could be accessed by SGR. Normally, APP SGR acts first upon mRNAs transcribed from the wild-type locus producing varied APP gencDNAs via an RNA intermediate and RT activity, requiring DNA strand breaks to enable retro-insertion. These gencDNA sequences then retro-insert into genomic DNA, generating cDNA-like sequences that lack introns. They may be full-length DNA copies of known APP splice variants (APP 571 and 695) or appear as truncated forms containing intra-exonic junctions. The insertion sites appear most commonly outside of wild-type loci, based upon DISH and initial insertion site analyses, with relatively few cells containing one or more copies. Normal SGR may represent a form of cellular memory, where activity-dependent transcription and DNA breaks of multiple etiologies enable the incorporation of gencDNAs, particularly as preferred and already-spliced forms that could later be reexpressed using similar or different promoters.

In disease, dysregulation of SGR occurs. It appears to involve coordinate actions of at least three SGR components: gene transcription, RT activity, and DNA strand breaks. Dysregulation then produces myriad numbers and forms of gencDNAs that could be neurotoxic via retro-insertion (as documented for other mobile elements; Horvath et al., 2017), other noncoding disruptions of RNA and DNA, and/or pathogenic APP proteins with altered primary, secondary, tertiary, or quaternary structure that would impact the functionality of APP, $A \beta$, and prion-like proteins. Known risk genes could be involved, for example, with APOE4 increasing APP transcription (Huang et al., 2017) that would, in turn, increase SGR. In this view, some classes of risk factor genes would promote SGR actions on AD "driver" or causal genes. Similarly, increased inflammation or oxidative stress would increase DNA strand breaks, resulting in more gencDNA retro-insertions into new, potentially deleterious genomic locations. Additional risk factors would increase pathogenic gencDNA variants in a feed-forward loop to increase gencDNA production that includes pathogenic SNVs known from familial cases, passing through a disease threshold. Other pathogenic SNVs not compatible with life (and familial AD manifestation) - and other genes-could also be produced in $\mathrm{SAD}$, while familial $\mathrm{AD}$ and Down syndrome pathology may also involve SGR, which could explain the decades of life still required to produce $\mathrm{AD}$ in these genetic disorders. SGR could generate prion-like sequences producing toxic protein accumulations in neuroanatomically defined patterns. Critically, SGR utilizes RT that appears to create SNVs through imprecise template copying and also identifies an accessible therapeutic strategy using Food and Drug Administration (FDA)-approved RT inhibitors (Lee and Chun, 2019).

\section{SGR AND OTHER BRAIN DISEASES}

The existence of SGR in the normal and the AD brain could potentially unify mechanisms for neurological and possibly neuropsychiatric sporadic brain diseases, where somatic, mosaic changes in DNA sequences generate pathogenic loci. Most other 
neurodegenerative and neuropsychiatric disorders, including AD-related dementias like FTLD and PD dementia/Lewy body dementia, present most commonly as a sporadic disease. SGR in theory could act on any number of gene loci, including those identified in familial disease to produce mosaic genomic variations that drive sporadic disease. Notably, new mutations in known pathogenic genes as well as in unrecognized genes could be somatically and mosaically altered in the brain, which again might be incompatible with life if present in the germline. SGR dysregulation could also explain the multiple decades it takes for most neurodegenerative diseases to progress as well as patient-to-patient variability in disease progression, wherein the generation and the accumulation of pathogenic gene variants occur mosaically over time. Similarly, SGR can explain the comorbidity of mixed dementias, where $\sim 50-$ $75 \%$ of patients with dementia have neuropathology from at least two of the AD-related dementias (Kovacs et al., 2013; James et al., 2016; Brenowitz et al., 2017; Kapasi et al., 2017). In this scenario, SGR could act on different genes within the same brain, affecting various cell types and neuroanatomical regions.

\section{SGR AND REVERSE TRANSCRIPTASE ACTIVITY}

The origin of brain RT activity is not yet clear. RTs were first discovered in retroviruses (Baltimore, 1970; Temin and Mizutani, 1970). However, a more likely source of endogenous RT activity in humans resides in the genome, within what was once called "junk DNA" (Ohno, 1972) and includes LINE1 sequences, human endogenous retrovirus (HERVs), and sequences encoding telomerases. LINE1 sequences account for $\sim 17 \%$ of the human genome and include over 500,000 copies (Lander et al., 2001). Two open reading frames within LINE1 are ORF1, thought to encode a high-affinity RNA binding protein, and ORF2 that encodes an RT and an endonuclease. A vast majority of these sequences are thought to be inactive; however, some have been shown to enable retro-transposition in cancer and have been implicated as a driver of evolution (Lee et al., 2012). LINE1 has also been hypothesized to contribute to neuronal diversity by disrupting existing genes or DNA elements upon re-insertion of LINE1 sequences during neurogenesis (Muotri et al., 2005), a concept that remains under active investigation (Evrony et al., 2012 vs. Upton et al., 2015). Another $8 \%$ of the genome is made up of HERVs that contain a possible RT within its pol gene, albeit with limited expected activity in the human genome (Nelson et al., 2003, 2004; Thomas et al., 2018). Human telomerase (encoded by the TERT gene) also has RT activity (Leao et al., 2018) and may further provide an RT source, as could other unknown enzymes.

\section{The Clinical Potential of SGR Inhibition in $A D$ and Other Brain Diseases}

The demonstrated involvement of RT activity in SGR implicates its inhibition as a possible $\mathrm{AD}$ preventative and/or therapeutic intervention. Critically, multiple FDA-approved RT inhibitors have been developed for the treatment of HIV (and later, HBV), with over three decades of continuous use as part of combination anti-retroviral therapies, which may provide real-world evidence of their efficacy in the prevention and/or treatment of AD. The number of treated HIV-infected patients who are also at risk of SAD (being $\sim 65$ years or older) currently number up to $\sim 80,000-100,000$ patients in the United States (CDC, 2018), which would yield an expected AD prevalence in the thousands $(10 \%$ of all persons age 65 or older have $\mathrm{AD}$; Alzheimer's Association, 2019). A surveillance of these patients has occurred for over a decade in anticipation of an increase of $\mathrm{AD}$ in HIV-infected patients (Alisky, 2007), yet only one documented $\mathrm{AD} / \mathrm{HIV}$-infected case has appeared in the peerreviewed literature (Turner et al., 2016). The limitations of post hoc epidemiology are acknowledged, and prospective AD clinical trials are needed. However, even if confounders resulted in these numbers being off by a factor of 100, there would still be a significant difference between the number of reported HIVinfected SAD cases $v s$. the expected prevalence of SAD in this age group. Since approved RT inhibitors have over 30 years of realworld human safety data, legal, off-label prescription by a licensed physician represents a promising option for $\mathrm{AD}$ patients where no effective and safe therapy currently exists.

\section{CONCLUSION}

Genomic mosaicism in the human brain is a biological fact that manifests through multiple forms of DNA sequence changes within single cells, from aneuploidies through SNVs. The recent discovery of SGR acting on APP provides functionality for genomic mosaicism through actions on a single gene, with both normal and disease implications. Normally, SGR may act as a form of cellular memory (Crick, 1984; Davis and Squire, 1984), where transcriptional activity and resulting DNA breaks may enable the retro-insertion of gencDNAs ready for reexpression as pre-spliced and varied $\mathrm{mRNAs}$ and diverse protein products: a form of long-lasting memory. SGR may also resemble forms of genomic "streamlining" that have been documented through phylogeny and contribute to species evolution (Roy and Gilbert, 2006). The dysregulation of SGR produces disease through increased numbers and forms of toxic gencDNAs, as illustrated by somatic, genomic changes documented in SAD brains. Importantly, the SGR hypothesis in $\mathrm{AD}$ does not reject the amyloid hypothesis outright but rather incorporates major features to modify the hypothesis while also accommodating other distinct hypotheses and explaining discrepancies in the scientific and clinical trial literature through the generation of $A P P$ variants and downstream molecular diversity. SGR presents a new source of potential therapeutics, some with near-term implications for the treatment and/or prevention of $\mathrm{AD}$ by use of FDA-approved medicines targeting endogenous brain RTs, an approach supported by human epidemiological data on older HIV-infected patients. SGR and its roles in AD represent a new step toward understanding the functions of genomic mosaicism in the normal, aging, and diseased brain. 


\section{AUTHOR CONTRIBUTIONS}

GK and JC wrote this manuscript.

\section{FUNDING}

The research reported in this publication was supported by the NIA of the National Institutes of Health under award number R56AG067489 (JC). This work was supported by non-Federal

\section{REFERENCES}

Alisky, J. M. (2007). The coming problem of HIV-associated Alzheimer's disease. Med. Hypotheses 69, 1140-1143. doi: 10.1016/j.mehy.2007.02.030

Alonso, A. D., Beharry, C., Corbo, C. P., and Cohen, L. S. (2016). Molecular mechanism of prion-like tau-induced neurodegeneration. Alzheimers Dement. 12, 1090-1097. doi: 10.1016/j.jalz.2015.12.014

Alzheimer's Association (2019). Alzheimer's disease facts and figures. Alzheimers Dement. 15, 321-387. doi: 10.1016/j.jalz.2019.01.010

Andersen, J. K. (2004). Oxidative stress in neurodegeneration: cause or consequence? Nat. Med. 10(Suppl.), S18-S25. doi: 10.1038/nrn1434

Anderson, R. M., Hadjichrysanthou, C., Evans, S., and Wong, M. M. (2017). Why do so many clinical trials of therapies for Alzheimer's disease fail? Lancet 390, 2327-2329. doi: 10.1016/S0140-6736(17)32399-91

Arendt, T., Bruckner, M. K., Mosch, B., and Losche, A. (2010). Selective cell death of hyperploid neurons in Alzheimer's disease. Am. J. Pathol. 177, 15-20. doi: 10.2353/ajpath.2010.090955

Arendt, T., Mosch, B., and Morawski, M. (2009). Neuronal aneuploidy in health and disease: a cytomic approach to understand the molecular individuality of neurons. Int. J. Mol. Sci. 10, 1609-1627. doi: 10.3390/ijms100 41609

Arndt, J. W., Qian, F., Smith, B. A., Quan, C., Kilambi, K. P., Bush, M. W., et al. (2018). Structural and kinetic basis for the selectivity of aducanumab for aggregated forms of amyloid-beta. Sci. Rep. 8:6412. doi: 10.1038/s41598-01824501-0

Arnold, S. E., Toledo, J. B., Appleby, D. H., Xie, S. X., Wang, L. S., Baek, Y., et al. (2013). Comparative survey of the topographical distribution of signature molecular lesions in major neurodegenerative diseases. J. Comp. Neurol. 521, 4339-4355. doi: 10.1002/cne.23430

Baker, A. M., Huang, W., Wang, X. M., Jansen, M., Ma, X. J., Kim, J., et al. (2017). Robust RNA-based in situ mutation detection delineates colorectal cancer subclonal evolution. Nat. Commun. 8:1998. doi: 10.1038/s41467-017-02295-5

Baltimore, D. (1970). RNA-dependent DNA polymerase in virions of RNA tumour viruses. Nature 226, 1209-1211. doi: 10.1038/2261209a0

Braak, H., Alafuzoff, I., Arzberger, T., Kretzschmar, H., and Del Tredici, K. (2006). Staging of Alzheimer disease-associated neurofibrillary pathology using paraffin sections and immunocytochemistry. Acta Neuropathol. 112, 389-404. doi: 10. 1007/s00401-006-0127-z

Braak, H., and Braak, E. (1991). Neuropathological stageing of Alzheimer-related changes. Acta Neuropathol. 82, 239-259. doi: 10.1007/bf00308809

Brenowitz, W. D., Keene, C. D., Hawes, S. E., Hubbard, R. A., Longstreth, W. T. Jr., Woltjer, R. L., et al. (2017). Alzheimer's disease neuropathologic change, Lewy body disease, and vascular brain injury in clinic- and community-based samples. Neurobiol. Aging 53, 83-92. doi: 10.1016/j.neurobiolaging.2017.01.017

Burki, T. (2018). Alzheimer's disease research: the future of bace inhibitors. Lancet 391:2486. doi: 10.1016/S0140-6736(18)31425-31429

Bushman, D. M., Kaeser, G. E., Siddoway, B., Westra, J. W., Rivera, R. R., Rehen, S. K., et al. (2015). Genomic mosaicism with increased amyloid precursor protein (APP) gene copy number in single neurons from sporadic Alzheimer's disease brains. eLife 4:e05116. doi: 10.7554/eLife. 05116

Carlsson, C. M. (2008). Lessons learned from failed and discontinued clinical trials for the treatment of Alzheimer's disease: future directions. J. Alzheimers Dis. 15, 327-338. doi: 10.3233/jad-2008-15214 funds from The Shaffer Family Foundation and The Bruce Ford and Anne Smith Bundy Foundation (JC). The content is solely the responsibility of the authors and does not necessarily represent the official views of the National Institutes of Health.

\section{ACKNOWLEDGMENTS}

We thank Dr. Laura Wolszon and Danielle Jones for their assistance in editing this manuscript.

Castro, M. A., Hadziselimovic, A., and Sanders, C. R. (2019). The vexing complexity of the amyloidogenic pathway. Protein Sci. 28, 1177-1193. doi: $10.1002 /$ pro. 3606

CDC (2018). Center for Disease Control and Prevention. HIV Surveillance Report, 2017. Available: http://www.cdc.gov/hiv/library/reports/hiv-surveillance.html (accessed October 1, 2019).

Chun, J. J., Schatz, D. G., Oettinger, M. A., Jaenisch, R., and Baltimore, D. (1991). The recombination activating gene-1 (RAG-1) transcript is present in the murine central nervous system. Cell 64, 189-200. doi: 10.1016/0092-8674(91) 90220-s

Crick, F. (1984). Memory and molecular turnover. Nature 312:101. doi: 10.1038/ $312101 \mathrm{a} 0$

Crystal, H., Dickson, D., Fuld, P., Masur, D., Scott, R., Mehler, M., et al. (1988). Clinico-pathologic studies in dementia: nondemented subjects with pathologically confirmed Alzheimer's disease. Neurology 38, 1682-1687. doi: 10.1212/wnl.38.11.1682

Cummings, J. L., Morstorf, T., and Zhong, K. (2014). Alzheimer's disease drugdevelopment pipeline: few candidates, frequent failures. Alzheimers Res. Ther. 6:37. doi: $10.1186 /$ alzrt269

Davis, H. P., and Squire, L. R. (1984). Protein synthesis and memory: a review. Psychol. Bull. 96, 518-559.

De Strooper, B., and Karran, E. (2016). The cellular phase of Alzheimer's disease. Cell 164, 603-615. doi: 10.1016/j.cell.2015.12.056

Dolan, P. J., and Johnson, G. V. (2010). The role of tau kinases in Alzheimer's disease. Curr. Opin. Drug Discov. Dev. 13, 595-603. doi: 10.6026/ 97320630091023

Egan, M. F., Kost, J., Tariot, P. N., Aisen, P. S., Cummings, J. L., Vellas, B., et al. (2018). Randomized trial of verubecestat for mild-to-moderate Alzheimer's disease. N. Engl. J. Med. 378, 1691-1703. doi: 10.1056/NEJMoa1706441

Eid, J., Fehr, A., Gray, J., Luong, K., Lyle, J., Otto, G., et al. (2009). Real-time DNA sequencing from single polymerase molecules. Science 323, 133-138. doi: 10.1126/science. 1162986

Eimer, W. A., Vijaya Kumar, D. K., Navalpur Shanmugam, N. K., Rodriguez, A. S., Mitchell, T., Washicosky, K. J., et al. (2018). Alzheimer's disease-associated betaamyloid is rapidly seeded by herpesviridae to protect against brain infection. Neuron 99, 56-63.e3. doi: 10.1016/j.neuron.2018.06.030

Eisenhofer, R., Minich, J. J., Marotz, C., Cooper, A., Knight, R., and Weyrich, L. S. (2019). Contamination in low microbial biomass microbiome studies: issues and recommendations. Trends Microbiol. 27, 105-117. doi: 10.1016/j.tim.2018. 11.003

Esparza, T. J., Zhao, H., Cirrito, J. R., Cairns, N. J., Bateman, R. J., Holtzman, D. M. et al. (2013). Amyloid-beta oligomerization in Alzheimer dementia versus high-pathology controls. Ann. Neurol. 73, 104-119. doi: 10.1002/ana.23748

Evrony, G. D., Cai, X., Lee, E., Hills, L. B., Elhosary, P. C., Lehmann, H. S., et al. (2012). Single-neuron sequencing analysis of L1 retrotransposition and somatic mutation in the human brain. Cell 151, 483-496. doi: 10.1016/j.cell.2012.09.035

Gao, Y., Sun, Y., Frank, K. M., Dikkes, P., Fujiwara, Y., Seidl, K. J., et al. (1998). A critical role for DNA end-joining proteins in both lymphogenesis and neurogenesis. Cell 95, 891-902. doi: 10.1016/s0092-8674(00)81714-81716

Gericke, G. S. (2008). An integrative view of dynamic genomic elements influencing human brain evolution and individual neurodevelopment. Med. Hypotheses 71, 360-373. doi: 10.1016/j.mehy.2008.03.048

Ghetti, B., Oblak, A. L., Boeve, B. F., Johnson, K. A., Dickerson, B. C., and Goedert, M. (2015). Invited review: frontotemporal dementia caused by 
microtubule-associated protein tau gene (MAPT) mutations: a chameleon for neuropathology and neuroimaging. Neuropathol. Appl. Neurobiol. 41, 24-46. doi: $10.1111 /$ nan. 12213

Gimbel, D. A., Nygaard, H. B., Coffey, E. E., Gunther, E. C., Lauren, J., Gimbel, Z. A., et al. (2010). Memory impairment in transgenic Alzheimer mice requires cellular prion protein. J. Neurosci. 30, 6367-6374. doi: 10.1523/JNEUROSCI. 0395- 10.2010

Glenner, G. G., and Wong, C. W. (1984a). Alzheimer's disease and Down's syndrome: sharing of a unique cerebrovascular amyloid fibril protein. Biochem. Biophys. Res. Commun. 122, 1131-1135. doi: 10.1016/0006-291x(84)91209

Glenner, G. G., and Wong, C. W. (1984b). Alzheimer's disease: initial report of the purification and characterization of a novel cerebrovascular amyloid protein. Biochem. Biophys. Res. Commun. 120, 885-890. doi: 10.1016/s0006-291x(84) 80190-80194

Goldgaber, D., Lerman, M. I., McBride, O. W., Saffiotti, U., and Gajdusek, D. C. (1987). Characterization and chromosomal localization of a cDNA encoding brain amyloid of Alzheimer's disease. Science 235, 877-880. doi: 10.1126/ science. 3810169

Harding, A., Gonder, U., Robinson, S. J., Crean, S., and Singhrao, S. K. (2017). Exploring the association between Alzheimer's disease, oral health, microbial endocrinology and nutrition. Front. Aging Neurosci. 9:398. doi: 10.3389/fnagi. 2017.00398

Hardy, J., and Selkoe, D. J. (2002). The amyloid hypothesis of Alzheimer's disease: progress and problems on the road to therapeutics. Science 297, 353-356. doi: $10.1126 /$ science. 1072994

Hardy, J. A., and Higgins, G. A. (1992). Alzheimer's disease: the amyloid cascade hypothesis. Science 256, 184-185. doi: 10.1126/science.1566067

Hebert, P. D. N., Braukmann, T. W. A., Prosser, S. W. J., Ratnasingham, S., deWaard, J. R., Ivanova, N. V., et al. (2018). A sequel to sanger: amplicon sequencing that scales. BMC Genomics 19:219. doi: 10.1186/s12864-018-46114613

Herrup, K. (2015). The case for rejecting the amyloid cascade hypothesis. Nat. Neurosci. 18, 794-799. doi: 10.1038/nn.4017

Hill, J. M., Clement, C., Pogue, A. I., Bhattacharjee, S., Zhao, Y., and Lukiw, W. J. (2014). Pathogenic microbes, the microbiome, and Alzheimer's disease (AD). Front. Aging Neurosci. 6:127. doi: 10.3389/fnagi.2014.00127

Holmes, B. B., and Diamond, M. I. (2014). Prion-like properties of Tau protein: the importance of extracellular Tau as a therapeutic target. J. Biol. Chem. 289, 19855-19861. doi: 10.1074/jbc.R114.549295

Hooli, B. V., Mohapatra, G., Mattheisen, M., Parrado, A. R., Roehr, J. T., Shen, Y., et al. (2012). Role of common and rare APP DNA sequence variants in Alzheimer disease. Neurology 78, 1250-1257. doi: 10.1212/WNL. 0b013e3182515972

Horvath, V., Merenciano, M., and Gonzalez, J. (2017). Revisiting the relationship between transposable elements and the eukaryotic stress response. Trends Genet. 33, 832-841. doi: 10.1016/j.tig.2017.08.007

Huang, Y. A., Zhou, B., Wernig, M., and Sudhof, T. C. (2017). ApoE2, ApoE3, and ApoE4 differentially stimulate APP transcription and abeta secretion. Cell 168, 427-441.e21. doi: 10.1016/j.cell.2016.12.044

Insel, P. S., Ossenkoppele, R., Gessert, D., Jagust, W., Landau, S., Hansson, O., et al. (2017). Time to amyloid positivity and preclinical changes in brain metabolism, atrophy, and cognition: evidence for emerging amyloid pathology in Alzheimer's disease. Front. Neurosci. 11:281. doi: 10.3389/fnins.2017. 00281

Iourov, I. Y., Vorsanova, S. G., Liehr, T., and Yurov, Y. B. (2009). Aneuploidy in the normal, Alzheimer's disease and ataxia-telangiectasia brain: differential expression and pathological meaning. Neurobiol. Dis. 34, 212-220. doi: 10.1016/ j.nbd.2009.01.003

Iourov, I. Y., Vorsanova, S. G., Yurov, Y. B., and Kutsev, S. I. (2019). Ontogenetic and pathogenetic views on somatic chromosomal mosaicism. Genes 10:379. doi: 10.3390/genes 10050379

Itzhaki, R. F., Lathe, R., Balin, B. J., Ball, M. J., Bearer, E. L., Braak, H., et al. (2016). Microbes and Alzheimer's disease. J. Alzheimers Dis. 51, 979-984. doi: 10.3233/JAD- 160152

James, B. D., Wilson, R. S., Boyle, P. A., Trojanowski, J. Q., Bennett, D. A., and Schneider, J. A. (2016). TDP-43 stage, mixed pathologies, and clinical Alzheimer's-type dementia. Brain 139, 2983-2993. doi: 10.1093/brain/aww224
Jaunmuktane, Z., Mead, S., Ellis, M., Wadsworth, J. D., Nicoll, A. J., Kenny, J., et al. (2015). Evidence for human transmission of amyloid-beta pathology and cerebral amyloid angiopathy. Nature 525, 247-250. doi: 10.1038/nature15369

Jin, M., Shepardson, N., Yang, T., Chen, G., Walsh, D., and Selkoe, D. J. (2011). Soluble amyloid beta-protein dimers isolated from Alzheimer cortex directly induce Tau hyperphosphorylation and neuritic degeneration. Proc. Natl. Acad. Sci. U.S.A. 108, 5819-5824. doi: 10.1073/pnas.1017033108

Kametani, F., and Hasegawa, M. (2018). Reconsideration of amyloid hypothesis and Tau hypothesis in Alzheimer's disease. Front. Neurosci. 12:25. doi: 10.3389/ fnins.2018.00025

Kapasi, A., DeCarli, C., and Schneider, J. A. (2017). Impact of multiple pathologies on the threshold for clinically overt dementia. Acta Neuropathol. 134, 171-186. doi: 10.1007/s00401-017-1717-1717

Katzman, R., Terry, R., DeTeresa, R., Brown, T., Davies, P., Fuld, P., et al. (1988). Clinical, pathological, and neurochemical changes in dementia: a subgroup with preserved mental status and numerous neocortical plaques. Ann. Neurol. 23, 138-144. doi: 10.1002/ana.410230206

Kaufman, S. K., Sanders, D. W., Thomas, T. L., Ruchinskas, A. J., Vaquer-Alicea, J., Sharma, A. M., et al. (2016). Tau prion strains dictate patterns of cell pathology, progression rate, and regional vulnerability in vivo. Neuron 92, 796-812. doi: 10.1016/j.neuron.2016.09.055

Kaushal, D., Contos, J. J., Treuner, K., Yang, A. H., Kingsbury, M. A., Rehen, S. K., et al. (2003). Alteration of gene expression by chromosome loss in the postnatal mouse brain. J. Neurosci. 23, 5599-5606. doi: 10.1523/JNEUROSCI. 23-13-05599.2003

Kelleher, R. J. III, and Shen, J. (2017). Presenilin-1 mutations and Alzheimer's disease. Proc. Natl. Acad. Sci. U.S.A. 114, 629-631. doi: 10.1073/pnas. 1619574114

Kingsbury, M. A., Friedman, B., McConnell, M. J., Rehen, S. K., Yang, A. H., Kaushal, D., et al. (2005). Aneuploid neurons are functionally active and integrated into brain circuitry. Proc. Natl. Acad. Sci. U.S.A. 102, 6143-6147. doi: 10.1073/pnas.0408171102

Kovacs, G. G., Milenkovic, I., Wohrer, A., Hoftberger, R., Gelpi, E., Haberler, C., et al. (2013). Non-Alzheimer neurodegenerative pathologies and their combinations are more frequent than commonly believed in the elderly brain: a community-based autopsy series. Acta Neuropathol. 126, 365-384. doi: 10.1007/ s00401-013-1157-y

Kunkle, B. W., Grenier-Boley, B., Sims, R., Bis, J. C., Damotte, V., Naj, A. C., et al. (2019). Genetic meta-analysis of diagnosed Alzheimer's disease identifies new risk loci and implicates Abeta, tau, immunity and lipid processing. Nat. Genet. 51, 414-430. doi: 10.1038/s41588-019-0358-352

Lake, B. B., Ai, R., Kaeser, G. E., Salathia, N. S., Yung, Y. C., Liu, R., et al. (2016). Neuronal subtypes and diversity revealed by single-nucleus RNA sequencing of the human brain. Science 352, 1586-1590. doi: 10.1126/science.aaf1204

Lake, B. B., Chen, S., Sos, B. C., Fan, J., Kaeser, G. E., Yung, Y. C., et al. (2018). Integrative single-cell analysis of transcriptional and epigenetic states in the human adult brain. Nat. Biotechnol. 36, 70-80. doi: 10.1038/nbt.4038

Lampson, B. C., Inouye, M., and Inouye, S. (2005). Retrons, msDNA, and the bacterial genome. Cytogenet. Genome Res. 110, 491-499. doi: 10.1159/ 000084982

Lander, E. S., Linton, L. M., Birren, B., Nusbaum, C., Zody, M. C., Baldwin, J., et al. (2001). Initial sequencing and analysis of the human genome. Nature 409, 860-921. doi: 10.1038/35057062

Lauren, J., Gimbel, D. A., Nygaard, H. B., Gilbert, J. W., and Strittmatter, S. M. (2009). Cellular prion protein mediates impairment of synaptic plasticity by amyloid-beta oligomers. Nature 457, 1128-1132. doi: 10.1038/nature 07761

Leao, R., Apolonio, J. D., Lee, D., Figueiredo, A., Tabori, U., and Castelo-Branco, P. (2018). Mechanisms of human telomerase reverse transcriptase (hTERT) regulation: clinical impacts in cancer. J. Biomed. Sci. 25:22. doi: 10.1186/s12929018-0422-428

Lee, E., Iskow, R., Yang, L., Gokcumen, O., Haseley, P., Luquette, L. J., et al. (2012). Landscape of somatic retrotransposition in human cancers. Science 337, 967-971. doi: 10.1126/science.1222077

Lee, M. H., and Chun, J. (2019). Mosaic APP gene recombination in Alzheimer's disease-what's next? J. Exp. Neurosci. 13:1179069519849669. doi: 10.1177/ 1179069519849669 
Lee, M.-H., Liu, C. S., Zhu, Y., Kaeser, G. E., Rivera, R., Romanow, W. J., et al. (2019). Reply: evidence that APP gene copy number changes reflect recombinant vector contamination. bioRxiv [preprint]. doi: 10.1101/730291

Lee, M. H., Siddoway, B., Kaeser, G. E., Segota, I., Rivera, R., Romanow, W. J., et al. (2018). Somatic APP gene recombination in Alzheimer's disease and normal neurons. Nature 563, 639-645. doi: 10.1038/s41586-018-0718-716

Leija-Salazar, M., Piette, C., and Proukakis, C. (2018). Review: somatic mutations in neurodegeneration. Neuropathol. Appl. Neurobiol. 44, 267-285. doi: 10.1111/ nan. 12465

Levy-Lahad, E., Wasco, W., Poorkaj, P., Romano, D. M., Oshima, J., Pettingell, W. H., et al. (1995). Candidate gene for the chromosome 1 familial Alzheimer's disease locus. Science 269, 973-977. doi: 10.1126/science.7638622

Liu, C. C., Zhao, N., Fu, Y., Wang, N., Linares, C., Tsai, C. W., et al. (2017). ApoE4 accelerates early seeding of amyloid pathology. Neuron 96, 1024-1032.e3. doi: 10.1016/j.neuron.2017.11.013

Mastroeni, D., Nolz, J., Sekar, S., Delvaux, E., Serrano, G., Cuyugan, L., et al. (2018). Laser-captured microglia in the Alzheimer's and Parkinson's brain reveal unique regional expression profiles and suggest a potential role for hepatitis B in the Alzheimer's brain. Neurobiol. Aging 63, 12-21. doi: 10.1016/j. neurobiolaging.2017.10.019

Mehta, D., Jackson, R., Paul, G., Shi, J., and Sabbagh, M. (2017). Why do trials for Alzheimer's disease drugs keep failing? A discontinued drug perspective for 2010-2015. Expert Opin. Investig. Drugs 26, 735-739. doi: 10.1080/13543784. 2017.1323868

Moore, S., Evans, L. D., Andersson, T., Portelius, E., Smith, J., Dias, T. B., et al. (2015). APP metabolism regulates tau proteostasis in human cerebral cortex neurons. Cell Rep. 11, 689-696. doi: 10.1016/j.celrep.2015.03.068

Morris, G. P., Clark, I. A., and Vissel, B. (2018). Questions concerning the role of amyloid-beta in the definition, aetiology and diagnosis of Alzheimer's disease. Acta Neuropathol. 136, 663-689. doi: 10.1007/s00401-018-1918-1918

Muotri, A. R., Chu, V. T., Marchetto, M. C., Deng, W., Moran, J. V., and Gage, F. H. (2005). Somatic mosaicism in neuronal precursor cells mediated by L1 retrotransposition. Nature 435, 903-910. doi: 10.1038/nature03663

Muotri, A. R., and Gage, F. H. (2006). Generation of neuronal variability and complexity. Nature 441, 1087-1093. doi: 10.1038/nature04959

Nelson, P. N., Carnegie, P. R., Martin, J., Davari Ejtehadi, H., Hooley, P., Roden, D., et al. (2003). Demystified. Human endogenous retroviruses. Mol. Pathol. 56, 11-18. doi: 10.1136/mp.56.1.11

Nelson, P. N., Hooley, P., Roden, D., Davari Ejtehadi, H., Rylance, P., Warren, P., et al. (2004). Human endogenous retroviruses: transposable elements with potential? Clin. Exp. Immunol. 138, 1-9. doi: 10.1111/j.1365-2249.2004.02592.x

Nunomura, A., Moreira, P. I., Castellani, R. J., Lee, H. G., Zhu, X., Smith, M. A., et al. (2012). Oxidative damage to RNA in aging and neurodegenerative disorders. Neurotox. Res. 22, 231-248. doi: 10.1007/s12640-012-9331-x

Nunomura, A., Perry, G., Pappolla, M. A., Wade, R., Hirai, K., Chiba, S., et al. (1999). RNA oxidation is a prominent feature of vulnerable neurons in Alzheimer's disease. J. Neurosci. 19, 1959-1964. doi: 10.1523/JNEUROSCI.1906-01959.1999

Ohno, S. (1972). So much "junk" DNA in our genome. Brookhaven Symp. Biol. 23, $366-370$.

Okamura, N., and Yanai, K. (2017). Brain imaging: applications of tau PET imaging. Nat. Rev. Neurol. 13, 197-198. doi: 10.1038/nrneurol.2017.38

Olsson, T. T., Klementieva, O., and Gouras, G. K. (2018). Prion-like seeding and nucleation of intracellular amyloid-beta. Neurobiol. Dis. 113, 1-10. doi: 10.1016/ j.nbd.2018.01.015

Ossenkoppele, R., Schonhaut, D. R., Scholl, M., Lockhart, S. N., Ayakta, N., Baker, S. L., et al. (2016). Tau PET patterns mirror clinical and neuroanatomical variability in Alzheimer's disease. Brain 139(Pt 5), 1551-1567. doi: 10.1093/ brain/aww027

Papavasiliou, F. N., and Schatz, D. G. (2002). Somatic hypermutation of immunoglobulin genes: merging mechanisms for genetic diversity. Cell 109(Suppl.), S35-S44. doi: 10.1016/s0092-8674(02)00706-707

Park, J. S., Lee, J., Jung, E. S., Kim, M. H., Kim, I. B., Son, H., et al. (2019). Brain somatic mutations observed in Alzheimer's disease associated with aging and dysregulation of tau phosphorylation. Nat. Commun. 10:3090. doi: 10.1038/ s41467-019-11000-11007

Peterson, S. E., Yang, A. H., Bushman, D. M., Westra, J. W., Yung, Y. C., Barral, S., et al. (2012). Aneuploid cells are differentially susceptible to caspase-mediated death during embryonic cerebral cortical development. J. Neurosci. 32, 1621316222. doi: 10.1523/JNEUROSCI.3706-12.2012

Potter, H. (1991). Review and hypothesis: Alzheimer disease and Down syndromechromosome 21 nondisjunction may underlie both disorders. Am. J. Hum. Genet. 48, 1192-1200.

Potter, H., Chial, H. J., Caneus, J., Elos, M., Elder, N., Borysov, S., et al. (2019). Chromosome instability and mosaic aneuploidy in neurodegenerative and neurodevelopmental disorders. Front. Genet. 10:1092. doi: 10.3389/fgene.2019. 01092

Potter, H., Granic, A., and Caneus, J. (2016). Role of Trisomy 21 mosaicism in sporadic and familial Alzheimer's disease. Curr. Alzheimer Res. 13, 7-17. doi: $10.2174 / 156720501301151207100616$

Rademakers, R., Cruts, M., and van Broeckhoven, C. (2004). The role of tau (MAPT) in frontotemporal dementia and related tauopathies. Hum. Mutat. 24, 277-295. doi: 10.1002/humu.20086

Rapoport, M., Dawson, H. N., Binder, L. I., Vitek, M. P., and Ferreira, A. (2002). Tau is essential to beta -amyloid-induced neurotoxicity. Proc. Natl. Acad. Sci. U.S.A. 99, 6364-6369. doi: 10.1073/pnas.092136199

Rehen, S. K., McConnell, M. J., Kaushal, D., Kingsbury, M. A., Yang, A. H., and Chun, J. (2001). Chromosomal variation in neurons of the developing and adult mammalian nervous system. Proc. Natl. Acad. Sci. U.S.A. 98, 13361-13366. doi: $10.1073 /$ pnas. 231487398

Rehen, S. K., Yung, Y. C., McCreight, M. P., Kaushal, D., Yang, A. H., Almeida, B. S., et al. (2005). Constitutional aneuploidy in the normal human brain. J. Neurosci. 25, 2176-2180. doi: 10.1523/JNEUROSCI.4560-04.2005

Rogaev, E. I., Sherrington, R., Rogaeva, E. A., Levesque, G., Ikeda, M., Liang, Y., et al. (1995). Familial Alzheimer's disease in kindreds with missense mutations in a gene on chromosome 1 related to the Alzheimer's disease type 3 gene. Nature 376, 775-778. doi: 10.1038/376775a0

Rohrback, S., Siddoway, B., Liu, C. S., and Chun, J. (2018). Genomic mosaicism in the developing and adult brain. Dev. Neurobiol. 78, 1026-1048. doi: 10.1002/ dneu. 22626

Rovelet-Lecrux, A., Hannequin, D., Raux, G., Le Meur, N., Laquerriere, A., Vital, A., et al. (2006). APP locus duplication causes autosomal dominant early-onset Alzheimer disease with cerebral amyloid angiopathy. Nat. Genet. 38, 24-26. doi: $10.1038 / \mathrm{ng} 1718$

Roy, S. W., and Gilbert, W. (2006). The evolution of spliceosomal introns: patterns, puzzles and progress. Nat. Rev. Genet. 7, 211-221. doi: 10.1038/nrg1807

Saunders, A. M., Strittmatter, W. J., Schmechel, D., George-Hyslop, P. H., PericakVance, M. A., Joo, S. H., et al. (1993). Association of apolipoprotein E allele epsilon 4 with late-onset familial and sporadic Alzheimer's disease. Neurology 43, 1467-1472. doi: 10.1212/wnl.43.8.1467

Scholl, M., Lockhart, S. N., Schonhaut, D. R., O’Neil, J. P., Janabi, M., Ossenkoppele, R., et al. (2016). PET imaging of tau deposition in the aging human brain. Neuron 89, 971-982. doi: 10.1016/j.neuron.2016.01.028

Selkoe, D. J., and Hardy, J. (2016). The amyloid hypothesis of Alzheimer's disease at 25 years. $E M B O$ Mol. Med. 8, 595-608. doi: 10.15252/emmm.201606210

Shepherd, C. E., Yang, Y., and Halliday, G. M. (2018). Region- and cell-specific aneuploidy in brain aging and neurodegeneration. Neuroscience 374, 326-334. doi: 10.1016/j.neuroscience.2018.01.050

Sherrington, R., Rogaev, E. I., Liang, Y., Rogaeva, E. A., Levesque, G., Ikeda, M., et al. (1995). Cloning of a gene bearing missense mutations in early-onset familial Alzheimer's disease. Nature 375, 754-760. doi: 10.1038/375754a0

Sleegers, K., Brouwers, N., Gijselinck, I., Theuns, J., Goossens, D., Wauters, J., et al. (2006). APP duplication is sufficient to cause early onset Alzheimer's dementia with cerebral amyloid angiopathy. Brain 129(Pt 11), 2977-2983. doi: 10.1093/brain/awl203

Solleiro-Villavicencio, H., and Rivas-Arancibia, S. (2018). Effect of chronic oxidative stress on neuroinflammatory response mediated by $\mathrm{CD} 4(+) \mathrm{T}$ cells in neurodegenerative diseases. Front. Cell Neurosci. 12:114. doi: 10.3389/fncel. 2018.00114

St George-Hyslop, P. H., Tanzi, R. E., Polinsky, R. J., Neve, R. L., Pollen, D., Drachman, D., et al. (1987). Absence of duplication of chromosome 21 genes in familial and sporadic Alzheimer's disease. Science 238, 664-666. doi: 10.1126/ science. 2890206

Strittmatter, W. J., Saunders, A. M., Schmechel, D., Pericak-Vance, M., Enghild, J., Salvesen, G. S., et al. (1993). Apolipoprotein E: high-avidity binding to betaamyloid and increased frequency of type 4 allele in late-onset familial Alzheimer 
disease. Proc. Natl. Acad. Sci. U.S.A. 90, 1977-1981. doi: 10.1073/pnas.90. 5.1977

Sun, L., Zhou, R., Yang, G., and Shi, Y. (2017). Analysis of 138 pathogenic mutations in presenilin-1 on the in vitro production of Abeta42 and Abeta40 peptides by gamma-secretase. Proc. Natl. Acad. Sci. U.S.A. 114, E476-E485. doi: 10.1073/pnas.1618657114

Tanzi, R. E., Bird, E. D., Latt, S. A., and Neve, R. L. (1987a). The amyloid beta protein gene is not duplicated in brains from patients with Alzheimer's disease. Science 238, 666-669. doi: 10.1126/science.2890207

Tanzi, R. E., Gusella, J. F., Watkins, P. C., Bruns, G. A., St George-Hyslop, P., Van Keuren, M. L., et al. (1987b). Amyloid beta protein gene: cDNA, mRNA distribution, and genetic linkage near the Alzheimer locus. Science 235, 880-884. doi: 10.1126/science.2949367

Temin, H. M., and Mizutani, S. (1970). RNA-dependent DNA polymerase in virions of Rous sarcoma virus. Nature 226, 1211-1213. doi: 10.1038/2261211a0

Thomas, J., Perron, H., and Feschotte, C. (2018). Variation in proviral content among human genomes mediated by LTR recombination. Mob DNA 9:36. doi: 10.1186/s13100-018-0142-143

Thomas, P., and Fenech, M. (2008). Chromosome 17 and 21 aneuploidy in buccal cells is increased with ageing and in Alzheimer's disease. Mutagenesis 23, 57-65. doi: 10.1093/mutage/gem044

Troncoso, J. C., Martin, L. J., Dal Forno, G., and Kawas, C. H. (1996). Neuropathology in controls and demented subjects from the Baltimore longitudinal study of aging. Neurobiol. Aging 17, 365-371. doi: 10.1016/01974580(96)00028-20

Turner, R. S., Chadwick, M., Horton, W. A., Simon, G. L., Jiang, X., and Esposito, G. (2016). An individual with human immunodeficiency virus, dementia, and central nervous system amyloid deposition. Alzheimers Dement. 4, 1-5. doi: 10.1016/j.dadm.2016.03.009

Upton, K. R., Gerhardt, D. J., Jesuadian, J. S., Richardson, S. R., Sanchez-Luque, F. J., Bodea, G. O., et al. (2015). Ubiquitous L1 mosaicism in hippocampal neurons. Cell 161, 228-239. doi: 10.1016/j.cell.2015.03.026
Watts, J. C., and Prusiner, S. B. (2018). beta-Amyloid prions and the pathobiology of Alzheimer's disease. Cold Spring Harb. Perspect. Med. 8:a023507. doi: 10. 1101/cshperspect.a023507

Westra, J. W., Barral, S., and Chun, J. (2009). A reevaluation of tetraploidy in the Alzheimer's disease brain. Neurodegener. Dis. 6, 221-229. doi: 10.1159/ 000236901

Westra, J. W., Rivera, R. R., Bushman, D. M., Yung, Y. C., Peterson, S. E., Barral, S., et al. (2010). Neuronal DNA content variation (DCV) with regional and individual differences in the human brain. J. Comp. Neurol. 518, 3981-4000. doi: $10.1002 /$ cne. 22436

Wiseman, F. K., Al-Janabi, T., Hardy, J., Karmiloff-Smith, A., Nizetic, D., Tybulewicz, V. L., et al. (2015). A genetic cause of Alzheimer disease: mechanistic insights from Down syndrome. Nat. Rev. Neurosci. 16, 564-574. doi: $10.1038 / \mathrm{nrn} 3983$

Yurov, Y. B., Vorsanova, S. G., Liehr, T., Kolotii, A. D., and Iourov, I. Y. (2014). X chromosome aneuploidy in the Alzheimer's disease brain. Mol. Cytogenet. 7:20. doi: 10.1186/1755-8166-7-20

Zhou, F., and Wang, D. (2017). The associations between the MAPT polymorphisms and Alzheimer's disease risk: a meta-analysis. Oncotarget 8 , 43506-43520. doi: 10.18632/oncotarget.16490

Conflict of Interest: JC is the co-founder of Mosaic Pharmaceuticals.

GK declare that the research was conducted in the absence of any commercial or financial relationships that could be construed as a potential conflict of interest.

Copyright (c) 2020 Kaeser and Chun. This is an open-access article distributed under the terms of the Creative Commons Attribution License (CC BY). The use, distribution or reproduction in other forums is permitted, provided the original author(s) and the copyright owner(s) are credited and that the original publication in this journal is cited, in accordance with accepted academic practice. No use distribution or reproduction is permitted which does not comply with these terms. 